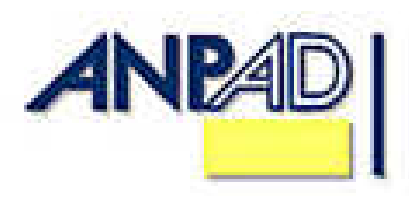

Disponível em

http://www.anpad.org.br/rac

RAC, Curitiba, v. 13, n. 2, art. 4,

p. 228-246, Abr./Jun. 2009

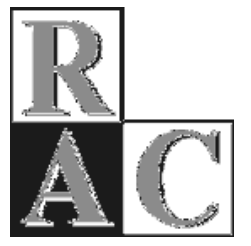

\title{
Os Modelos Multiestágios de Maturidade: um Breve Relato de sua História, sua Difusão e sua Aplicação na Gestão de Pessoas por meio do People Capability Maturity Model (P-CMM)
}

The Maturity Multi-Level Models: a Brief Report of its History, Dissemination and Application on People Management by People Capability Maturity Model (P-CMM)

Victor Natanael Schwetter Silveira*

Mestre em Administração pela UFMG. Professor na FNH, Belo Horizonte/MG, Brasil.

* Endereço: Victor Natanael Schwetter Silveira

Rua Curitiba, 832, sala 1105, Centro, Belo Horizonte/MG, 30170-120. E-mail: victornss@uai.com.br

Copyright @ 2009 RAC. Todos os direitos, inclusive de tradução, são reservados. É permitido citar parte de artigos sem autorização prévia desde que seja identificada a fonte. 


\title{
RESUMO
}

O objetivo deste artigo teórico é discutir o desenvolvimento e a aplicação de modelos multiestágios de maturidade nas organizações e, em particular, o modelo de maturidade People Capability Maturity Model ou PCMM (Curtis, Hefley, \& Miller, 1995, 2002), uma metodologia inovadora que busca mensurar o nível de maturidade em gestão de pessoas nas organizações. A partir de um esforço de pesquisa bibliográfica do tema, o artigo, de caráter teórico e exploratório, recupera o desenvolvimento histórico recente dos modelos de maturidade e apresenta suas principais contribuições. Inicialmente são apresentados os fundamentos teóricos dos modelos baseados em estágios. Em seguida discute-se a difusão desses modelos na área organizacional. Finalmente, apresenta-se o modelo P-CMM e discute-se sua metodologia e aplicação. Observa-se que o P-CMM promove um diagnóstico e uma orientação dos processos organizacionais, mensurando a progressão dos estágios de maturidade, orientando, em cada estágio, as práticas consistentes para desenvolver, organizar e gerar a melhoria contínua na gestão das pessoas.

Palavras-chave: modelos multiestágio; modelos de maturidade; melhoria contínua; P-CMM; gestão de pessoas.

\begin{abstract}
The aim of this theoretical article is to discuss the development and application of maturity multilevels models on people management in organizations, specifically, the People Capability Maturity Model or P-CMM (Curtis, Hefley, \& Miller, 1995, 2002), an innovating methodology to measure the maturity level on people management in organizations. Starting from a bibliographic research effort about this subject, the article, featured on a theoretical and explorative approach, recovers recent historical development of maturity models and shows its main contributions. Initially, the multilevel models theoretical bases are introduced. On sequence, the dissemination of these models on organizational field is overviewed. Finally, the People Capability Maturity Model is introduced and its methods and application are examined. In conclusion, it is evidenced that the PCMM can provide a diagnostic view and an organizational processes orientation, measuring the maturity level advance and providing, at each level, the best practices to develop, organize and to stimulate the continuous improvement on people management.
\end{abstract}

Key words: multilevel models; maturity models; P-CMM; continuous improvement; people management. 


\section{INTRODUÇÃO}

Os estudos sobre o desenvolvimento e crescimento das organizações geraram teorias que buscaram compreender a dinâmica do amadurecimento das empresas ao longo do tempo, tentando identificar padrões mais ou menos previsíveis acerca das mudanças presentes e futuras no comportamento e na estrutura organizacional. Dentre essas teorias surgiram abordagens que tentaram identificar aspectoschave em cada momento histórico das empresas e, a partir daí, organizaram descrições e agrupamentos de características que pudessem responder antecipadamente às possíveis mudanças a serem enfrentadas ao longo da existência organizacional, balizando eficazmente a ação gerencial.

Diante da perspectiva de compreender o comportamento organizacional no decorrer de sua existência, foram desenvolvidos os modelos baseados em estágios sucessivos de evolução aplicados às organizações. Tais modelos partiram do conceito fundamental de maturidade, que se refere ao desenvolvimento completo ou condição perfeita de algum processo ou atividade (Urdang \& Flexner, 1968). A maturidade conota, assim, o entendimento sobre os motivos pelos quais o sucesso organizacional é alcançado, assim como os caminhos para corrigir ou prevenir problemas que poderiam impedir a melhoria dos processos em uma perspectiva longitudinal e incremental.

A premissa geral que embasa os modelos de estágios de maturidade aplicados às organizações é a de que os processos de trabalho podem ser estruturados pelas empresas a partir de estágios ou níveis de evolução, sendo claramente definidos, gerenciados e controlados ao longo do tempo.

Além do mais, os modelos de maturidade utilizam o conceito de nível de maturidade. Este se refere à medida de efetividade ou à capacidade em qualquer processo específico, sendo descrito em termos de níveis de desempenho total ou capacidade máxima naquele processo. Assim, o nível de maturidade relaciona-se ao nível de capacidade organizacional obtido a partir da transformação e evolução de um ou mais domínios de processos em certa organização (Curtis, Hefley, \& Miller, 1995).

Atualmente, diante da necessidade de as empresas criarem processos organizacionais - e dentre eles os processos de gestão de pessoas - capazes de gerar competitividade, aumento de qualidade, redução de custos e alinhamento estratégico, ocorreu a difusão e expansão dos modelos baseados em estágios de maturidade em várias áreas organizacionais.

No campo da gestão de pessoas um modelo baseado em estágios de maturidade, que vem ganhando espaço e notoriedade, é o People Capability Maturity Model ou P-CMM (Curtis et al., 1995, 2002). Trata-se de um modelo multiestágio que tem por objetivo orientar, planejar e mensurar a efetiva aplicação das pessoas nas organizações. O P-CMM teve sua origem teórica em conceitos e práticas advindos de áreas como a qualidade total, as melhores práticas de gestão de pessoas, o desenvolvimento de competências e a aprendizagem organizacional.

Neste artigo teórico busca-se, inicialmente, apresentar os fundamentos e difusão dos modelos baseados em estágios. Em seguida, são brevemente discutidos os modelos baseados em estágios desenvolvidos para compreender os ciclos de vida das empresas, os processos de melhoria contínua, assim como os modelos de gerenciar projetos de empresas de tecnologia de informação. Depois, é abordada a expansão dos modelos baseados em estágios no início do século XXI, apresentando-se, na sequiência, os modelos baseados em estágios de maturidade e a gestão de pessoas e, em especial, o modelo multiestágio de maturidade People Capability Maturity Model [P-CMM], que será discutido com maior profundidade. 


\section{FUNDAMENTOS DOS MODELOS BASEADOS EM ESTÁGIOS}

Os estudos sobre desenvolvimento por meio de estágios mostram-se relevantes por fornecerem uma base para a formulação de teorias em várias áreas do conhecimento, trazendo em seus pressupostos as noções de desenvolvimento, crescimento ou evolução. Observa-se, entretanto, que os conceitos de desenvolvimento, crescimento e evolução não são meros sinônimos, ainda que guardem estreita relação entre si, como bem aponta Laszlo (2003). Segundo o autor, o desenvolvimento refere-se a uma melhoria nas condições gerais ou qualidade de um aspecto ou elemento, a partir de objetivos considerados desejáveis, fornecendo estados mais ou menos subjetivos e relativos sobre o que é ou não desenvolvido. O crescimento refere-se a um aumento no tamanho ou quantidade de um dado aspecto ou elemento, a partir de medidas baseadas em unidades definíveis de tamanho ou escala. Já a evolução refere-se a um processo de mudança direcional que impulsiona uma tendência no sentido de aumentar a complexidade estrutural e a simplicidade funcional, produzindo modos de operação mais eficientes, ajustados e com dinâmica mais harmoniosa (Laszlo, 2003).

Buscando gerar diretrizes formais para uma teoria dos modelos de estágios, Kuznets (1965) afirmou que os modelos baseados em estágios pressupõem que os elementos nos sistemas empresariais evoluem por meio de padrões de estágios distintos, que se sucedem em determinados períodos de tempo e podem ser objetivamente descritos.

Segundo Kuznets (1965), os modelos baseados em estágios devem obedecer a, pelo menos, duas condições fundamentais: (1) as características de cada estágio devem ser distintas e empiricamente testáveis; (2) o relacionamento analítico de cada estágio, com seu predecessor ou sucessor, deve ser bem definido, possibilitando identificar os processos que impulsionam o elemento de um estágio para outro.

Depreendem-se das diretrizes de Kuznets duas características-chave na formulação da teoria de estágios: (1) a exigência de identificação clara dos elementos e (2) a concepção de que seu crescimento se dá por meio de um continuum de tempo. Em relação à primeira característica, observase que o aspecto principal em relação a um determinado elemento é que ele deve partir de um status genérico para um campo particular e, ao mesmo tempo, o elemento pode ser especificado por um conjunto de atributos. Quanto à segunda característica-chave, trata-se de um aspecto do elemento que muda tanto quanto seus atributos se expandem ou se contraem em número e natureza.

Assim, torna-se relevante, ao se considerar uma teoria de estágios, identificar as variáveis que se organizam para gerar determinada configuração em cada nível e, além do mais, identificar os aspectos e características que sinalizam a mudança de um estágio para outro no decorrer do tempo.

Avançando na descrição formal das diretrizes para os modelos baseados em estágios, Lavoie e Culbert (1978) afirmaram que esses modelos devem atender aos seguintes requisitos: a) devem ser seqüenciais em sua natureza; b) devem ocorrer como progressão hierárquica que não é facilmente reversível; e c) devem envolver ampla gama de atividades e, também, a maior parte da estrutura organizacional.

Dessa forma, os modelos baseados em estágios se estruturam com base em processo evolutivo marcado por fases distintas que se encadeiam de forma crescente e, uma vez atingido um estágio de desenvolvimento superior, torna-se menos provável o seu retrocesso ao estágio predecessor. Além do mais, a mudança evolutiva produzida pela escalada dos estágios afeta integralmente o organismo ou estrutura, alterando qualitativamente sua configuração e suas características.

Ainda assim, cabe ressaltar que os modelos baseados em estágios não obedecem a um darwinismo social rígido, em que a evolução da organização acontece invariavelmente no sentido positivo e crescente, podendo ocorrer, em função de diversos fatores externos ou internos à organização, 
involuções e retornos a estágios anteriores de maturidade, produzindo retrocessos no decorrer da sucessão dos estágios evolutivos.

\section{DifusÃo dos MOdelos BASEAdOS EM ESTÁGIOS}

A partir do final da década de 1960 e início da década de 1970, começaram a se difundir modelos baseados em estágios, sendo aplicados ao campo de estudo das organizações e a outras áreas do conhecimento (Smith, Mitchell, \& Summer, 1985).

No campo do comportamento organizacional um dos primeiros autores a abordar modelos baseados em níveis evolutivos foi Kohlberg (1969). Esse autor desenvolveu um modelo para descrever o desenvolvimento moral dos indivíduos, definindo níveis crescentes do processo de aquisição da consciência moral. Em sua abordagem considerou o julgamento moral como a maneira pela qual uma pessoa resolve dilemas e toma decisões, valendo-se de um fundamento ético.

De acordo com Kohlberg (1969), os estágios de maturidade moral representam esquemas cognitivos qualitativamente diferenciáveis, seqüenciais, integrados hierarquicamente e considerados universais. $\mathrm{O}$ indivíduo teria de passar seqüencialmente pelos distintos níveis, integrando as estruturas prévias de pensamento num sistema mais complexo e com maior capacidade para lidar com aspectos abstratos e conceituais. Para sistematizar esses aspectos distintos, o autor descreveu três níveis de maturidade moral: pré-convencional, convencional e pós-convencional, cada um deles constituído por dois estágios. Assim, chegou a um total de seis estágios progressivos de desenvolvimento moral.

Na abordagem de Kohlberg (1969) a compreensão de julgamentos morais avançados é condição necessária, mas não suficiente, para que o indivíduo tenha comportamento eticamente adequado, condizente com níveis morais mais avançados. As normas, ou seja, regras de conduta advindas de construtos sociais, são gradativamente internalizadas pelos indivíduos que, assim, dispensam a presença de controlador externo, isto é, aquele que aplica e faz cumprir as normas.

Duas décadas depois, partindo da teoria de Kohlberg (1969), Petrick e Wagley (1992) criaram um modelo de maturidade moral - baseado em três estágios e seis níveis morais — aplicado às organizações. Dentro do Estágio I de Kohlberg, os autores inseriram os níveis 1 e 2 de maturidade moral. No nível 1 há o medo da extinção organizacional e a urgência da sobrevivência financeira dita a conduta moral dos indivíduos. Aceita-se como norma o uso direto da força. No nível 2 os ganhos obtidos pela organização guiam as ações dos indivíduos e os objetivos sucedidos justificam os meios. No Estágio II inseriram os níveis 3 e 4 de maturidade moral; no nível 3 a preocupação da organização é com a tradição de procedimentos operacionais padronizados e os pares profissionais pressionam-se mutuamente, para que haja adesão às normas sociais que definem o que certo e o que é errado. No nível 4 a orientação vinda da autoridade legal da organização determina o padrão moral vigente, ou seja, o que é certo e o que é errado baseia-se em decisões daqueles que detêm o poder hierárquico formal. Finalmente, no Estágio III inseriram os níveis 5 e 6 de maturidade moral. No nível 5 ocorre a participação dos indivíduos nos processos de tomadas de decisão e a confiança nas regras ditadas pela maioria torna-se o padrão moral organizacional, enquanto no nível 6 a justiça e os direitos individuais são ideais morais buscados pela organização. Assim, o julgamento equilibrado dos interesses em conflito molda o caráter organizacional que, por sua vez, determina a correção ou a incorreção do comportamento.

Segundo os autores, uma administração estratégica responsável ainda não existe nos dois primeiros estágios, pois há carência de consideração do acionista, carência de confiança moral e carência de consideração do impacto ecológico das relações humanas. Sem forte liderança moral, as organizações podem institucionalizar a mediocridade no planejamento estratégico, nas formulações das políticas e na implementação dos procedimentos. Assim, grupos informais podem permanecer fixados no nível 3 e oferecerem lealdade primeiro aos objetivos departamentais — antes que à missão organizacional - 
prioridades sociais e conteúdos ecológicos, correndo o risco de a organização se transformar numa coleção de sub-culturas territoriais, cada uma defendendo seus próprios interesses.

A importância em se determinar o nível moral nas organizações está na possibilidade de os administradores gerenciarem melhor o clima organizacional, produzindo códigos de conduta e capacidade de avaliar os comportamentos (Petrick \& Wagley, 1992). Além do mais, a maturidade moral capacita a empresa a resolver conflitos e racionalizar o processo de tomada de decisão diante de dilemas e situações imprevistas, bem como estimula sistemas de feedback e comunicação multi-nível em toda a rede de relacionamentos na organização.

Observa-se que um elemento essencial aos modelos multiestágios aplicados ao comportamento organizacional é a idéia de que o amadurecimento organizacional se relaciona direta e significativamente, com um processo crescente de desenvolvimento do raciocínio gerencial, permitindo que se caracterize o trabalho de gestão a partir de estágios crescentes de evolução, passando de um nível básico de gerenciamento até um nível superior e racionalizado na organização.

A partir da década de 1970, expandiu-se significativamente a aplicação dos modelos baseados em estágios evolutivos, sendo utilizados na compreensão de mais fenômenos organizacionais, como, por exemplo, os ciclos de vida das empresas.

\section{OS MOdelos BASEAdOS EM ESTÁGIOS E OS CICLOS DE VIDA DAS EMPRESAS}

No campo organizacional os modelos baseados em estágios passaram a ser usados para descrever os ciclos de vida das empresas. As diversas abordagens que enfocaram os ciclos de vida das organizações valeram-se de modelos baseados em estágios para explicitar suas concepções e tais abordagens adotaram como premissa a idéia de que padrões ou configurações previsíveis - em termos de estágios - estão sempre presentes no crescimento e amadurecimento das organizações (Smith et al., 1985). Dessa forma, concebem que existem certas regularidades no amadurecimento empresarial e essas regularidades ocorrem de tal forma que o processo de desenvolvimento da organização colabora, ele mesmo, para a segmentação da maturidade em estágios ou períodos de tempo (Scott, 1971). Além do mais, cada estágio no ciclo de vida pode ser definido a partir de uma característica-chave que identifica o estágio em particular (Smith et al., 1985).

Observa-se que os modelos baseados em estágios aplicados às teorias de ciclos de vida das empresas não são tão recentes na literatura organizacional (Chandler, 1962; Haire, 1959). Pode-se identificar Haire (1959) como um dos primeiros autores a propor que as organizações se desenvolveriam seguindo estágios organizados em algum padrão uniforme. Chandler (1962), a partir de uma perspectiva similar, introduziu a idéia de estágios no ciclo de vida das empresas em um modelo estruturado, a partir da percepção de que os estágios de desenvolvimento mudavam e com eles mudavam também as estruturas e as estratégias organizacionais relacionadas.

Desde então, diversos autores estruturaram modelos multiestágios para representar os ciclos de vida das organizações como Abernathy (1976), Adizes (1979), Galbraith (1982), Greiner (1972), Kimberly e Miles (1980), Marques (1994), Mintzberg (1973), Mount, Zinger e Forsyth (1993), Scott (1971) e Scott e Bruce (1987). Cada um desses modelos identifica certas características que tipificam as organizações em diferentes números de estágios de desenvolvimento. Cabe salientar que, apesar da singularidade de cada modelo e de diferirem em termos do número de estágios propostos, é possível verificar que o desenvolvimento das organizações se mostra como a razão direta de dois fatores fundamentais: flexibilidade e controlabilidade. A forma e o equilíbrio a ser conseguido entre estes dois itens é que caracterizarão as fases ou etapas de cada um dos modelos de ciclo de vida organizacional. 


\section{Os Modelos BaSEAdos em EstágIOS e a MelHORIa ContínuA}

Dentro do referencial da qualidade destaca-se o modelo proposto por Bressant, Caffyn e Gallagher (2001), um modelo baseado em níveis diferenciados de maturidade em melhoria contínua. Segundo os autores, a melhoria contínua pode ser definida como um processo de inovação incremental, focada e contínua, que envolve a totalidade da empresa.

Bressant et al. (2001) definiram cinco níveis de maturidade que são associados com o desenvolvimento das habilidades de melhoria contínua (ver Tabela 1).

Tabela 1: Modelo de Maturidade em Melhoria Contínua de Bressant, Caffyn e Gallagher

\begin{tabular}{|c|c|c|}
\hline Nível & Título & Características \\
\hline Nível 1 & $\begin{array}{l}\text { Pré interesse na } \\
\text { melhoria } \\
\text { contínua }\end{array}$ & $\begin{array}{l}\text { não existe uma estrutura formal para a melhoria na organização, sendo os } \\
\text { problemas solucionados ao acaso, sempre visando um benefício apenas } \\
\text { de curto prazo. Além disso, não existem estratégias de impacto nos } \\
\text { recursos humanos, como treinamento, desenvolvimento e } \\
\text { reconhecimento. }\end{array}$ \\
\hline Nível 2 & $\begin{array}{l}\text { Melhoria } \\
\text { contínua } \\
\text { estruturada }\end{array}$ & $\begin{array}{l}\text { existe um comitê formal para construir um sistema que desenvolverá a } \\
\text { melhoria contínua na empresa, contando com a participação dos } \\
\text { funcionários nas atividades, mesmo essas não sendo integradas às } \\
\text { operações do dia-a-dia. Os funcionários são treinados nas ferramentas } \\
\text { básicas de melhoria e o sistema de reconhecimento é introduzido. }\end{array}$ \\
\hline Nível 3 & $\begin{array}{l}\text { Melhoria } \\
\text { contínua } \\
\text { dirigida para } \\
\text { meta }\end{array}$ & $\begin{array}{l}\text { existe uma utilização formal dos objetivos estratégicos, sendo as } \\
\text { atividades de melhoria continua parte das atividades gerais de } \\
\text { administração. }\end{array}$ \\
\hline Nível 4 & $\begin{array}{l}\text { Melhoria } \\
\text { contínua pro- } \\
\text { ativa }\end{array}$ & $\begin{array}{l}\text { existe uma tendência para se desenvolver autonomamente e os indivíduos } \\
\text { e grupos gerenciam e direcionam seus próprios processos. Neste nível, as } \\
\text { responsabilidades da melhoria contínua são devolvidas para a unidade de } \\
\text { solução de problemas. }\end{array}$ \\
\hline Nível 5 & $\begin{array}{l}\text { Capacidade } \\
\text { completa de } \\
\text { melhoria } \\
\text { contínua }\end{array}$ & $\begin{array}{l}\text { aproximação do modelo de aprendizagem organizacional, existindo a } \\
\text { identificação e solução sistemática de problemas e compartilhamento do } \\
\text { aprendizado. }\end{array}$ \\
\hline
\end{tabular}

A relevância da utilização de um modelo multiestágio de maturidade em melhoria contínua relaciona-se, principalmente, ao fato de que a classificação dessas habilidades permite às empresas identificarem sua posição em relação às demais e, a partir desta constatação, desenvolver um plano para expandir suas habilidades de melhoria contínua, planejar e desenvolver sua qualidade nos processos organizacionais.

\section{Os Modelos Baseados em Estágios Aplicados aos Projetos de Tecnologia de INFORMAÇÃO}

No contexto das organizações envolvidas com o planejamento de sistemas e tecnologias de informação e informática os modelos multiestágios de maturidade ganharam força com a expansão da aplicação da informática e de tecnologias avançadas no meio empresarial. Com a necessidade crescente de gerar projetos e sistemas de informática e telecomunicações para atender às organizações 
públicas, privadas e sistemas militares, surgiu também a exigência de maiores níveis de confiabilidade, economia e eficácia na consecução de projetos tecnológicos e implementação de sistemas de informação. Dessa forma, os modelos multiestágios de maturidade passaram a constituir um arcabouço teórico importante, permitindo às organizações definirem passos seqüenciais com alto nível de detalhamento e controle, melhorando a gestão e a eficiência dos processos. Dentre os modelos que se destacam podem-se identificar os modelos de Nolan (1973), Burn (1994) e, mais recentemente, o modelo Capability Maturity Model, ou CMM (Carnegie-Mellon University, 2000).

De especial interesse aqui, o Capability Maturity Model ou CMM (Carnegie-Mellon University, 2000) foi desenvolvido por pesquisadores do Instituto de Engenharia de Software [SEI] da CarnegieMellon University, em 1986, a pedido do Departamento de Defesa dos Estados Unidos. Os pesquisadores do SEI foram incumbidos de desenvolver uma metodologia confiável que permitisse avaliar as capacidades dos prestadores de serviço na área de desenvolvimento de softwares. Isso se fazia necessário em função da necessidade de sistematizar os processos críticos de concepção e desenvolvimento de softwares para sistemas estratégicos de defesa que, em decorrência de sua natureza, são projetos complexos e suscetíveis em relação a qualificação dos profissionais envolvidos (Carnegie-Mellon University, 2000).

O Capability Maturity Model teve como fundamentação conceitual os princípios e práticas da qualidade total, inspirando-se, inicialmente, no modelo de mensuração da qualidade gerencial desenvolvido por Crosby em 1979 (ver Tabela 2). Posteriormente, Humphrey (1997) contribuiu para difusão do modelo CMM e seus derivados, com a versão do CMM para o gerenciamento de pessoas, o People Capability Maturity Model (P-CMM).

\section{Tabela 2: Aferidor de Maturidade da Gerência de Qualidade de Crosby}

\begin{tabular}{|c|c|c|c|c|c|}
\hline $\begin{array}{c}\text { Categorias de } \\
\text { Medida }\end{array}$ & $\begin{array}{l}\text { Estágio I } \\
\text { Incerteza }\end{array}$ & $\begin{array}{l}\text { Estágio II } \\
\text { Despertar }\end{array}$ & $\begin{array}{c}\text { Estágio III } \\
\text { Esclarecimento }\end{array}$ & $\begin{array}{l}\text { Estágio IV } \\
\text { Sabedoria }\end{array}$ & $\begin{array}{l}\text { Estágio V } \\
\text { Certeza }\end{array}$ \\
\hline $\begin{array}{l}\text { Compreensão } \\
\text { e atitude da } \\
\text { gerência }\end{array}$ & $\begin{array}{l}\text { Nenhuma } \\
\text { compreensão da } \\
\text { qualidade como } \\
\text { instrumento da } \\
\text { gerência. } \\
\text { Tendência a } \\
\text { culpar o } \\
\text { departamento de } \\
\text { qualidade pelos } \\
\text { "problemas de } \\
\text { qualidade". }\end{array}$ & $\begin{array}{l}\text { Reconhecimento } \\
\text { de que a } \\
\text { gerência da } \\
\text { qualidade é útil, } \\
\text { mas, não há } \\
\text { disposição para } \\
\text { gastar dinheiro } \\
\text { ou tempo } \\
\text { necessários à } \\
\text { realização. }\end{array}$ & $\begin{array}{l}\text { No decorrer do } \\
\text { programa de } \\
\text { melhoria da } \\
\text { qualidade, } \\
\text { aprenda mais } \\
\text { sobre gerência } \\
\text { da qualidade; dê } \\
\text { apoio e seja útil. }\end{array}$ & $\begin{array}{l}\text { Participe. } \\
\text { Compreenda os } \\
\text { absolutos da } \\
\text { gerência } \\
\text { qualidade. } \\
\text { Reconheça o seu } \\
\text { papel pessoal na } \\
\text { continuação da } \\
\text { ênfase. }\end{array}$ & $\begin{array}{l}\text { Considere a } \\
\text { gerência da } \\
\text { qualidade } \\
\text { parte } \\
\text { essencial da } \\
\text { companhia. }\end{array}$ \\
\hline $\begin{array}{l}\text { Status de } \\
\text { qualidade da } \\
\text { empresa }\end{array}$ & $\begin{array}{l}\text { A qualidade está } \\
\text { oculta nos } \\
\text { setores de } \\
\text { produção ou } \\
\text { engenharia. A } \\
\text { inspeção não } \\
\text { existe, } \\
\text { provavelmente, } \\
\text { na empresa. } \\
\text { Ênfase em } \\
\text { avaliação e } \\
\text { classificação. }\end{array}$ & $\begin{array}{l}\text { Nomeação de } \\
\text { um líder mais } \\
\text { forte para a } \\
\text { qualidade, } \\
\text { porém, a ênfase } \\
\text { continua em } \\
\text { avaliação de } \\
\text { movimento do } \\
\text { produto. } \\
\text { Continua no } \\
\text { setor de } \\
\text { produção ou } \\
\text { outro qualquer. }\end{array}$ & $\begin{array}{l}\text { O departamento } \\
\text { da qualidade } \\
\text { presta contas à } \\
\text { alta gerência, } \\
\text { toda a avaliação } \\
\text { é incorporada e } \\
\text { o gerente tem } \\
\text { um papel na } \\
\text { administração } \\
\text { da companhia. }\end{array}$ & $\begin{array}{l}\text { O gerente da } \\
\text { qualidade é um } \\
\text { funcionário da } \\
\text { companhia; } \\
\text { comunicação } \\
\text { efetiva de status } \\
\text { e ação } \\
\text { preventiva. } \\
\text { Envolvimento } \\
\text { com negócios } \\
\text { de consumidor e } \\
\text { encargos } \\
\text { especiais. }\end{array}$ & $\begin{array}{l}\text { Gerente de } \\
\text { qualidade na } \\
\text { diretoria. A } \\
\text { prevenção é a } \\
\text { maior } \\
\text { preocupação. } \\
\text { A qualidade } \\
\text { é idéia } \\
\text { prioritária. }\end{array}$ \\
\hline
\end{tabular}


(conclusão)

Tabela 2: Aferidor de Maturidade da Gerência de Qualidade de Crosby

\begin{tabular}{|c|c|c|c|c|c|}
\hline $\begin{array}{c}\text { Categorias de } \\
\text { Medida }\end{array}$ & $\begin{array}{l}\text { Estágio I } \\
\text { Incerteza }\end{array}$ & $\begin{array}{l}\text { Estágio II } \\
\text { Despertar }\end{array}$ & $\begin{array}{c}\text { Estágio III } \\
\text { Esclarecimento }\end{array}$ & $\begin{array}{l}\text { Estágio IV } \\
\text { Sabedoria }\end{array}$ & $\begin{array}{l}\text { Estágio V } \\
\text { Certeza }\end{array}$ \\
\hline $\begin{array}{l}\text { Resolução de } \\
\text { problema }\end{array}$ & $\begin{array}{l}\text { Problemas são } \\
\text { combatidos à } \\
\text { medida que } \\
\text { ocorrem; } \\
\text { nenhuma } \\
\text { solução; } \\
\text { definição } \\
\text { inadequada; } \\
\text { gritos e } \\
\text { acusações. }\end{array}$ & $\begin{array}{l}\text { Organização de } \\
\text { equipes para } \\
\text { solucionar } \\
\text { principais } \\
\text { problemas. } \\
\text { Soluções em } \\
\text { longo prazo não } \\
\text { solicitadas. }\end{array}$ & $\begin{array}{l}\text { Comunicação de } \\
\text { ação corretiva } \\
\text { estabelecida. } \\
\text { Problemas } \\
\text { enfrentados com } \\
\text { franqueza e } \\
\text { resolvidos de } \\
\text { modo ordeiro. }\end{array}$ & $\begin{array}{l}\text { Problemas } \\
\text { identificados em } \\
\text { estágio precoce } \\
\text { de } \\
\text { desenvolviment } \\
\text { o. Todas as } \\
\text { funções abertas } \\
\text { a sugestões e } \\
\text { melhoria. }\end{array}$ & $\begin{array}{l}\text { Problemas } \\
\text { evitados, } \\
\text { exceto nos } \\
\text { casos mais } \\
\text { extra- } \\
\text { ordinários }\end{array}$ \\
\hline $\begin{array}{l}\text { Custo de } \\
\text { qualidade } \\
\text { como \% das } \\
\text { vendas }\end{array}$ & $\begin{array}{l}\text { Registrado: } \\
\text { desconhecido } \\
\text { Real: } 20 \%\end{array}$ & $\begin{array}{l}\text { Registrado: } 3 \% \\
\text { Real: } 18 \%\end{array}$ & $\begin{array}{l}\text { Registrado: } 8 \% \\
\text { Real: } 12 \%\end{array}$ & $\begin{array}{l}\text { Registrado: } \\
6,5 \% \\
\text { Real: } 8 \%\end{array}$ & $\begin{array}{l}\text { Registrado: } \\
2,5 \% \\
\text { Real: } 2,5 \%\end{array}$ \\
\hline $\begin{array}{l}\text { Medidas de } \\
\text { melhoria da } \\
\text { qualidade }\end{array}$ & $\begin{array}{l}\text { Nenhuma } \\
\text { atividade } \\
\text { organizada. } \\
\text { Nenhuma } \\
\text { compreensão } \\
\text { dessas } \\
\text { atividades. }\end{array}$ & $\begin{array}{l}\text { Tentativas } \\
\text { óbvias de } \\
\text { "motivação" em } \\
\text { curto prazo. }\end{array}$ & $\begin{array}{l}\text { Implementação } \\
\text { de programa de } \\
14 \text { etapas com } \\
\text { total } \\
\text { compreensão e } \\
\text { determinação de } \\
\text { cada etapa. }\end{array}$ & $\begin{array}{l}\text { Continuação do } \\
\text { programa de } 14 \\
\text { etapas e início } \\
\text { do Certifique- } \\
\text { se. }\end{array}$ & $\begin{array}{l}\text { A melhoria } \\
\text { da qualidade } \\
\text { é uma } \\
\text { atividade } \\
\text { normal e } \\
\text { contínua. }\end{array}$ \\
\hline $\begin{array}{l}\text { Sumário das } \\
\text { possibilidades } \\
\text { da companhia } \\
\text { no setor da } \\
\text { qualidade }\end{array}$ & $\begin{array}{l}\text { "Não sei por } \\
\text { que temos } \\
\text { problemas de } \\
\text { qualidade". }\end{array}$ & $\begin{array}{l}\text { "Será } \\
\text { absolutamente } \\
\text { necessário ter } \\
\text { sempre } \\
\text { problemas de } \\
\text { qualidade?". }\end{array}$ & $\begin{array}{l}\text { "Através do } \\
\text { compromisso da } \\
\text { gerência e da } \\
\text { melhoria da } \\
\text { qualidade, } \\
\text { estamos } \\
\text { identificando e } \\
\text { resolvendo os } \\
\text { nossos } \\
\text { problemas". }\end{array}$ & $\begin{array}{l}\text { "A prevenção de } \\
\text { defeitos é parte } \\
\text { rotineira da } \\
\text { nossa } \\
\text { operação". }\end{array}$ & $\begin{array}{l}\text { "Sabemos } \\
\text { por que não } \\
\text { temos } \\
\text { problemas de } \\
\text { qualidade". }\end{array}$ \\
\hline
\end{tabular}

Fonte: Crosby (1979, pp. 50-51).

O CMM segue a lógica do modelo de Crosby, propondo uma estrutura de cinco níveis que permitem estratificar a posição ocupada pela empresa desenvolvedora de softwares com relação à maturidade de seus processos de gerenciamento de projetos (ver Figura 1). 
Figura 1: Níveis de Maturidade do Modelo CMM

\begin{tabular}{|l|l|}
\hline NÍVEIS DE MATURIDADE DO MODELO CMM \\
\begin{tabular}{|l} 
Nível de \\
Maturidade 5 \\
Otimizado
\end{tabular} & $\begin{array}{l}\text { Práticas baseadas em melhoria contínua } \\
\text { Processos são melhorados continuamente com base em uma } \\
\text { compreen são quantitativa e abrangente das causas da variação. }\end{array}$ \\
$\begin{array}{l}\text { Nível de } \\
\text { Maturidade } 4 \\
\text { Previsível }\end{array}$ & $\begin{array}{l}\text { Práticas mensuradas } \\
\text { Processos são medidos e controlados utilizando } \\
\text { estatística e outras técnicas quantitativas. }\end{array}$ \\
$\begin{array}{l}\text { Nível de } \\
\text { Maturidade } 3 \\
\text { Definido }\end{array}$ & $\begin{array}{l}\text { Práticas baseadas em competências } \\
\text { Processos são caracterizados, entendidos e descritos } \\
\text { em padrões, ferramentas e métodos pela organização. }\end{array}$ \\
$\begin{array}{l}\text { Nível de } \\
\text { Maturidade 2 } \\
\text { Gerenciado }\end{array}$ & $\begin{array}{l}\text { Práticas repetidas } \\
\text { Processos são plan ejados, executados, medidos } \\
\text { e controlados pela organização. }\end{array}$ \\
$\begin{array}{l}\text { Mível de } \\
\text { Maturidade 1 }\end{array}$ & $\begin{array}{l}\text { Práticas caóticas } \\
\text { Processos são imprevisíveis, reativos e } \\
\text { pobremente controlados pela organização. }\end{array}$ \\
\hline
\end{tabular}

Fonte: adaptado de Curtis et al. (1995, p. 30).

Outra experiência importante no desenvolvimento de modelos de maturidade aplicados às empresas de tecnologia pode ser creditada ao Project Management Institute [PMI]. No final do ano de 2003, esse instituto tornou mundialmente conhecido o modelo OPM3 - Organizational Project Management Maturity Model (PMI, 2005), que possibilita às empresas produzir e reproduzir com sucesso, e de forma consistente ao longo do tempo, um alto desempenho no gerenciamento de projetos. O objetivo do OPM3 é permitir às empresas a visualização das capacidades necessárias, para que possam implementar suas estratégias com consistência e previsibilidade.

\section{A EXPANSÃo dos MOdelos BASEAdOS EM ESTÁGIOS No INÍCIO do SÉCULO XXI}

Nos primeiros anos do século XXI uma variedade de modelos baseados em níveis de maturidade, similares à metodologia do $\mathrm{CMM}$, começou a ser desenvolvida, como se pode constatar em modelos como o Contract Management Maturity Model (Garrett \& Rendon, 2005), o Documentation Process Maturity (Visconti \& Cook, 1998), o Human Factors Integration Capability Maturity Model (Earthy, Bowler, Forster, \& Taylor, 1999), o Online Course Design Maturity Model (Neuhauser, 2004), o Supply Chain Management Process Maturity Model (Lockamy \& Mccormack, 2004). Basicamente, todos eles apontam um caminho lógico de progressivo desenvolvimento da capacitação em processos gerenciais. Para a maioria desses modelos o importante não é definir em que nível uma determinada empresa se encontra, mas o que deve ser feito para assegurar a continuidade de seu desenvolvimento e a melhoria contínua e controlada de seus processos.

Constata-se que existem hoje modelos de maturidade para aumentar a capacidade de uma empresa em alguma área específica, para desenvolver e gerenciar software e engenharia de sistemas, para 
integrar equipes de produtos, para desenvolver cadeias logísticas e para desenvolver recursos humanos e a gestão de pessoas, entre outras aplicações.

\section{Os Modelos Baseados em Estágios de Maturidade e a Gestão de Pessoas}

Os modelos multiestágios de maturidade somente recentemente começaram a ser aplicados aos recursos humanos nas organizações (Curtis et al., 2003), o que pode estar relacionado ao fato de que, tradicionalmente, a gestão de pessoas manteve pouca relação com as esferas estratégicas, limitando-se a atuar como prestadora de serviços internos (Dutra, 2002). Entretanto, a partir da década de 1990, diante de um ambiente cada vez mais dinâmico e pouco previsível, as organizações passaram a buscar novos conhecimentos e gerir as suas competências individuais e organizacionais, reconfigurando a gestão da força de trabalho e incorporando concretamente a participação dos indivíduos nas decisões e o seu comprometimento e contribuição para a melhoria contínua (Dutra, 2002).

Observa-se que a gestão de pessoas nas organizações recebeu estímulos para desenvolver metodologias efetivas, confiáveis e dotadas de indicadores de mensuração para orientar a ação e aplicação dos funcionários no trabalho. Além do mais, a exigência de melhoria contínua dos processos passou a requerer uma crescente melhoria na capacidade gerencial das organizações e um maior controle e eficácia na aplicação dos recursos. Assim, a busca por novas metodologias capazes de dotar a empresa e os indivíduos de maiores capacidades incentivou alguns autores a produzirem estudos condizentes com as novas necessidades da gestão de pessoas nas organizações. Nessa perspectiva os modelos multi-estágios começaram a ganhar adesão de pesquisadores da área de recursos humanos.

Quanto aos modelos multiestágios que abordam a gestão de pessoas nas organizações, podem ser identificados, principalmente, os modelos Human Factors Integration Capability Maturity Model (Earthy et al., 1999) e o People Capability Maturity Model (Curtis et al., 1995, 2002).

O Human Factors Integration Capability Maturity Model (Earthy, Bowler, Forster, \& Taylor, 1999) busca garantir a qualidade em processos industriais, fornecendo os meios para a erradicação de riscos de segurança no trabalho que podem afetar a produtividade com base nas normas ISO. Trata-se de um modelo que tem aplicação ergonômica no trabalho, indicando, em uma escala de maturidade, os níveis crescentes de melhoria da produtividade, desde a instrução dos indivíduos para reconhecerem problemas e riscos, gerenciamento da capacidade dos funcionários, até o nível final de institucionalização de um alto padrão de qualidade sem riscos humanos.

O People Capability Maturity Model (Curtis et al., 1995, 2002) apresenta-se como estrutura baseada em cinco níveis de maturidade que estabelecem as bases para uma melhoria contínua das competências individuais e do desenvolvimento de equipes de trabalho, orientando a aplicação das pessoas.

Observa-se que o único dos modelos a abordar a gestão das pessoas por completo, enfocando todos os processos relacionados à área de recursos humanos, é o People Capability Maturity Model. Esse modelo permite que se consiga evitar a introdução de práticas de trabalho para as quais os profissionais da organização não estejam preparados para implementar efetivamente, atuando preventivamente contra o desgaste desnecessário dos indivíduos em práticas ou ações ineficazes e, simultaneamente, indicando quando e onde investir corretamente, tornando o desempenho dos indivíduos mais eficaz e econômico. Além do mais, o P-CMM permite a identificação de áreas-chave a serem desenvolvidas em cada nível de maturidade e o momento correto de sua implementação ou correção. Assim, a arquitetura em estágios reconhece a dificuldade das organizações em melhorar todos os seus processos simultaneamente e oferece, em função disso, uma seqüência de estados intermediários que possam ser atingidos em tempo relativamente curto. O detalhamento do modelo PCMM será visto na seção seguinte. 


\section{O Modelo Multiestágio de Maturidade People Capability Maturity Model (P- CMM)}

A partir do modelo de maturidade CMM os pesquisadores Bill Curtis, William Hefley e Sally Miller desenvolveram, em 1995, o People Capability Maturity Model, ou P-CMM. O People Capability Maturity Model surgiu como modelo que emprega a mesma metodologia básica de mensuração de processos utilizada no CMM para avaliar e orientar as melhores práticas de gerenciar e desenvolver a gestão de pessoas nas organizações.

O P-CMM foi estruturado segundo uma sucessão de estágios que vão desde o nível 1 até o nível 5 e cada nível de maturidade foi construído como um platô evolutivo bem definido que institucionaliza novas capacidades para o desenvolvimento da força de trabalho da organização. Os níveis foram desenhados seguindo os seguintes critérios: 1) devem representar fases históricas razoáveis, na vida de uma organização; 2) devem prover degraus intermediários de maturidade, em seqüência satisfatória; 3 ) devem sugerir medidas de progresso e objetivos intermediários; 4) devem definir prioridades de melhoria nos estágios.

Segue-se abaixo a descrição das características de cada nível do modelo.

A organização Nível 1 (Inicial). As organizações nesse nível, costumeiramente, apresentam dificuldades em reter indivíduos talentosos. As organizações imaturas são pobremente equipadas para responder à escassez de talentos. As práticas de trabalho nestas organizações podem ser freqüentemente consideradas caóticas e inconsistentes. Em algumas áreas, a organização não tem práticas de trabalho definidas e, em outras áreas, não tem treinado os indivíduos responsáveis por executar as práticas existentes. Estas organizações tipicamente apresentam quatro características: a) inconsistência em executar as práticas existentes; b) falta de responsabilidade e capacitação dos gerentes e funcionários; c) práticas seguindo certos costumes ou práticas por hábito; d) equipes sem envolvimento emocional.

Geralmente os gerentes e supervisores nas organizações imaturas são mal preparados para executar suas responsabilidades de trabalho. Seu treinamento gerencial é frágil e, quando provido, tende a cobrir somente aquelas práticas de trabalho respaldadas na legislação. A organização pode tipicamente prover formulários para guiar as atividades de trabalho, como avaliação de desempenho. Entretanto, muito freqüentemente, pouco treinamento é oferecido para conduzir as atividades preconizadas por estes formulários.

Tais organizações assumem implicitamente que a habilidade de gerenciamento é inata ou adquirida, por meio da observação de outros gerentes. Entretanto, se os gerentes são inconsistentes em gerenciar seu pessoal, novos gerentes irão aprender a partir de modelos inconsistentes. O primeiro passo na mudança deste estado é preparar gerentes para serem responsáveis pela capacitação e desenvolvimento de todos os subordinados diretos.

A organização Nível 2 (Gerenciado). As práticas de trabalho nesse nível estão focadas nas atividades no nível dos departamentos ou setores de trabalho. O primeiro passo é preparar os gerentes para assumir as atividades de trabalho, como as responsabilidades de alta prioridade para o seu emprego. Eles devem aceitar como responsabilidade pessoal o desenvolvimento e o desempenho de todos aqueles que executam trabalhos na sua unidade. As práticas implementadas no nível 2 voltam-se para a atenção que os gerentes dão aos problemas no nível da unidade, como os seguintes: recrutamento, comprometimento da coordenação, provisão de recursos, gestão de desempenho, desenvolvimento de habilidades e tomadas de decisão sobre remuneração e compensação.

Se as pessoas são incapazes de executar o trabalho designado, as práticas de trabalho sofisticadas serão de pouco benefício. No nível 2 de maturidade, os gerentes são vigilantes para qualquer tipo de 
problema que prejudique o desempenho em suas unidades. Os problemas que contribuem para que as pessoas deixem de executar eficazmente suas atividades incluem os seis seguintes: a) sobrecarga de trabalho; b) distrações no ambiente de trabalho; c) objetivos de desempenho e feedback obscuros; d) falta de conhecimento ou habilidade relevantes; e) comunicação ineficiente; f) moral baixo.

Um dos primeiros benefícios que as organizações experimentam, quando elas implementam as melhorias dirigidas pelo P-CMM, é a redução da rotatividade voluntária. No nível 2 de maturidade, o $\mathrm{P}-\mathrm{CMM}$ direciona uma das mais freqüentes causas da rotatividade: o relacionamento empobrecido com a chefia. Quando os indivíduos percebem um ambiente de trabalho mais racional e organizado, tendem a se envolver e permanecer na organização.

A organização Nível 3 (Definido). As organizações nesse nível percebem que, mesmo executando as práticas básicas de trabalho, existem inconsistências em como estas práticas são executadas pelos departamentos ou setores e há também pouca sinergia pela estrutura da organização. Perdem-se oportunidades em padronizar as práticas de trabalho, porque o conhecimento comum e as habilidades necessárias para conduzir as atividades do negócio ainda não foram identificadas.

Neste nível, a organização constrói uma metodologia abrangente das competências de trabalho que estabelecem a arquitetura de trabalho da organização. Cada competência de trabalho é um elemento desta arquitetura, e a dependência entre os processos baseados em competência descreve como estes elementos da arquitetura interagem. Como resultado, as práticas de trabalho tornam-se mecanismos que facilitam o alinhamento contínuo de acordo com as mudanças nos objetivos do negócio.

Uma cultura organizacional comum é desenvolvida de maneira que a organização consegue atingir o nível Definido. Essa cultura deve ser construída com um entendimento comum de conhecimento e habilidades necessárias para serem desenvolvidas para atingir os níveis superiores de desempenho e a definição de processos baseados na competência que cada indivíduo executa. Estas competências de trabalho sendo estratégicas para o negócio, a organização reforça esta importância, desenvolvendo-as e recompensando-as. Como resultado, toda a força de trabalho começa a compartilhar a responsabilidade para desenvolver níveis maiores de capacitação das competências de trabalho da organização. As práticas de trabalho implementadas anteriormente no nível 2 são agora padronizadas e adaptadas, neste nível, para encorajar e recompensar o crescimento das competências dos indivíduos e grupos.

A organização Nível 4 (Previsível). A organização nesse nível já estabeleceu uma metodologia para desenvolver seu trabalho. Aqui a organização gerencia e explora a capacitação criada pela metodologia de competências de trabalho. A organização torna-se capaz de gerenciar a capacitação e o desempenho quantitativamente; pode prever a capacitação requerida para executar o trabalho, porque ela pode quantificar a capacitação de sua força de trabalho e os processos baseados na competência que são utilizados para executar suas atividades. Além disso, para explorar as possibilidades abertas pela metodologia de competência, a organização começa a gerenciar a sua capacitação quantitativamente. Em cada unidade de trabalho, o desempenho dos processos mais críticos, baseados em competências para alcançar os objetivos do negócio, são medidos e utilizados para estabelecer linhas-base do desempenho dos processos que poderão ser utilizados para o gerenciamento dos processos, baseados em competência, fazendo o julgamento necessário para as ações corretivas.

A organização Nível 5 (Otimizado). Nesse último nível toda a organização está focada na melhoria contínua. Estas melhorias são feitas para a capacitação dos indivíduos e grupos de trabalho, para o melhor desempenho dos processos baseados em competência e para as práticas e atividades do trabalho. A organização usa os resultados das atividades do gerenciamento quantitativo estabelecido no Nível 4 para orientar as melhorias no Nível 5.

As entradas para melhorias potenciais das práticas de trabalho surgem de várias fontes. Elas podem vir de lições aprendidas na criação de melhorias das atividades do trabalho em uma unidade, de sugestões dadas pela força de trabalho, ou de resultados das atividades do gerenciamento quantitativo. A organização avalia continuamente as práticas de trabalho e tecnologias para identificar todas as que 
têm potencial de contribuir para os objetivos de melhoria. Os dados sobre a efetividade das práticas de trabalho que emergiram das atividades de gerenciamento quantitativo são usados para analisar melhorias potenciais de desempenho das práticas inovadoras ou de mudanças propostas. Práticas inovadoras que demonstraram grande potencial para melhoria são identificadas e avaliadas em aplicações de teste. Se elas provarem eficiência, serão desenvolvidas pela organização.

A capacitação do trabalho das organizações Nível 5 é melhorada continuamente. Essa melhoria acontece por meio de avanços incrementais nas práticas de trabalho existentes e da adoção de práticas inovadoras e tecnologias que podem ter impacto significativo. A cultura criada na organização orienta os indivíduos para que cada um se esforçe para melhorar sua própria capacitação, contribuindo para o bom desempenho da organização.

Observa-se que cada nível de maturidade é composto por diversas áreas de processo, e cada área de processo, por sua vez, contém um conjunto de objetivos que, quando alcançados, estabelecem que a área atingiu o nível ótimo ou maduro de capacitação. Para atingir esses objetivos a organização deve implementar um conjunto de práticas, que descrevem procedimentos gerenciais e técnicos bem definidos para cada área de processo no P-CMM.

Existem vinte e duas áreas de processo nos cinco níveis de maturidade do P-CMM (ver Tabela 3). Com exceção do nível 1, cada nível de maturidade é composto por um conjunto de áreas de processo e cada área de processo designa: a) uma descrição rápida da área; b) os objetivos da área; c) as práticas prescritas para a área.

Tabela 3: Estrutura Geral dos Níveis de Maturidade do P-CMM

\begin{tabular}{|c|c|c|c|c|}
\hline Nível & Foco & Objetivos & $\begin{array}{l}\text { Tipo de } \\
\text { Prática }\end{array}$ & Áreas de Processo \\
\hline $\begin{array}{l}\text { Nível } 1 \\
\text { Inicial }\end{array}$ & Não há & Não há & Não há & Não há \\
\hline \multirow{6}{*}{$\begin{array}{l}\text { Nível } 2 \\
\text { Gerenciado }\end{array}$} & \multirow{6}{*}{$\begin{array}{l}\text { Gestão das } \\
\text { pessoas }\end{array}$} & \multirow{6}{*}{$\begin{array}{l}\text { Gestão e } \\
\text { desenvolvimento } \\
\text { da equipe pelos } \\
\text { gerentes }\end{array}$} & \multirow{6}{*}{$\begin{array}{l}\text { Práticas } \\
\text { repetitivas } \\
\text { (rotineiras) }\end{array}$} & Provimento de pessoal \\
\hline & & & & Comunicação e coordenação \\
\hline & & & & Ambiente de trabalho \\
\hline & & & & Gestão do desempenho \\
\hline & & & & Treinamento e desenvolvimento \\
\hline & & & & Remuneração \\
\hline \multirow{7}{*}{$\begin{array}{l}\text { Nível 3 } \\
\text { Definido }\end{array}$} & \multirow{7}{*}{$\begin{array}{l}\text { Gestão das } \\
\text { competências } \\
\text { das pessoas }\end{array}$} & \multirow{7}{*}{$\begin{array}{l}\text { Desenvolvimento } \\
\text { de competências } \\
\text { e grupos de } \\
\text { trabalho, } \\
\text { alinhando-os aos } \\
\text { objetivos e } \\
\text { estratégias do } \\
\text { negócio. }\end{array}$} & \multirow{7}{*}{$\begin{array}{l}\text { Práticas } \\
\text { baseadas em } \\
\text { competências }\end{array}$} & Análise de competências \\
\hline & & & & Planejamento dos recursos humanos \\
\hline & & & & Desenvolvimento de competências \\
\hline & & & & Desenvolvimento de carreiras \\
\hline & & & & $\begin{array}{l}\text { Desenvolvimento de práticas-baseadas- } \\
\text { em-competências }\end{array}$ \\
\hline & & & & Desenvolvimento de grupos de trabalho \\
\hline & & & & Cultura participativa \\
\hline \multirow{6}{*}{$\begin{array}{l}\text { Nível } 4 \\
\text { Previsível }\end{array}$} & \multirow{6}{*}{$\begin{array}{l}\text { Gestão das } \\
\text { capacidades } \\
\text { da empresa }\end{array}$} & \multirow{6}{*}{$\begin{array}{l}\text { Integração das } \\
\text { competências no } \\
\text { trabalho e } \\
\text { gerenciamento } \\
\text { quantitativo do } \\
\text { desempenho. }\end{array}$} & \multirow{6}{*}{$\begin{array}{l}\text { Práticas } \\
\text { mensuradas }\end{array}$} & Integração de competências \\
\hline & & & & Grupos de trabalho autônomos \\
\hline & & & & Ativos baseados em competências \\
\hline & & & & Gestão quantitativa do desempenho \\
\hline & & & & Gestão da capacidade organizacional \\
\hline & & & & Orientação e aconselhamento \\
\hline
\end{tabular}


(conclusão)

Tabela 3: Estrutura Geral dos Níveis de Maturidade do P-CMM

\begin{tabular}{|c|c|c|c|c|}
\hline Nível & Foco & Objetivos & $\begin{array}{l}\text { Tipo de } \\
\text { Prática }\end{array}$ & Áreas de Processo \\
\hline \multirow{3}{*}{$\begin{array}{l}\text { Nível } 5 \\
\text { Otimizado }\end{array}$} & \multirow{3}{*}{$\begin{array}{l}\text { Gestão das } \\
\text { mudanças na } \\
\text { empresa }\end{array}$} & \multirow{3}{*}{$\begin{array}{l}\text { Instauração da } \\
\text { melhoria contínua } \\
\text { dos processos e } \\
\text { alinhamento do } \\
\text { grupo de trabalho } \\
\text { com a capacidade } \\
\text { organizacional }\end{array}$} & \multirow{3}{*}{$\begin{array}{l}\text { Práticas } \\
\text { baseadas em } \\
\text { melhoria } \\
\text { contínua }\end{array}$} & Melhoria contínua da capacidade \\
\hline & & & & $\begin{array}{l}\text { Alinhamento do desempenho } \\
\text { organizacional }\end{array}$ \\
\hline & & & & $\begin{array}{l}\text { Inovação contínua dos recursos } \\
\text { humanos }\end{array}$ \\
\hline
\end{tabular}

Fonte: adaptado de Curtis et al. (1995, p. 50).

Em cada área de processo são descritos objetivos e estes são desmembrados em práticas de implementação e práticas de institucionalização. As primeiras referem-se às práticas e procedimentos implementados pela organização para satisfazer os objetivos de uma área de processo, enquanto as últimas se referem aos procedimentos implementados para assegurar que a organização tenha a manutenção do compromisso e a capacidade para desempenhar as práticas e atividades de trabalho da organização. No total o modelo P-CMM descreve 22 áreas de processo, subdivididas em 87 objetivos que, por sua vez, são subdivididos em 246 práticas de implementação e 252 práticas de institucionalização.

As práticas de implementação foram desenhadas para estabelecer melhorias em grupos ou indivíduos, ou mesmo para executar avaliações dos procedimentos, enquanto as práticas de institucionalização formam um sistema de travas organizacionais, que dificultam o retrocesso das práticas de implementação a estados anteriores de maturidade.

As atividades de institucionalização são divididas nos seguintes grupos: a) comprometimento em executar, ou seja, condições que garantem a permanência da melhoria dos processos; b) capacitação para executar, relacionada aos fatores que contribuem para que a área seja efetivamente implantada, compreendendo estruturas organizacionais, recursos e treinamento; c) medição e análise que designam medições básicas requeridas para avaliar o status da área-chave; d) verificação da implementação, ou seja, um conjunto de ações que garantem a conformidade das demais atividades com os processos estabelecidos.

Ao se considerar as aplicações do P-CMM, observa-se que estas ainda são poucas, mas foram relatadas aplicações do modelo em empresas como Boeing, Lockheed Martin, BAE Systems, além de empresas de software na Índia (Curtis et al., 2003). A aplicação do P-CMM objetivava nessas organizações a redução do excessivo turnover em seus quadros profissionais. O elevado índice de rotatividade de pessoal comprometia a capacidade técnica e fazia com que as empresas perdessem competências estratégicas e pessoal altamente qualificado. Segundo os autores a redução do turnover tem sido significativa, especialmente entre as empresas indianas, que se tornaram as mais recentes empresas a ingressar nos níveis 4 e 5, segundo a classificação do P-CMM. Há também o relato de Vakaslahti (1997), que aplicou uma versão reduzida do P-CMM em pequenas empresas finlandesas, na tentativa de desenvolver uma abordagem simplificada para uso integrado com outros processos gerenciais, como ações de planejamento. Seus resultados confirmaram que o uso sistemático do PCMM, orientando as linhas de ação, melhorou significativamente o desempenho das pequenas empresas.

Os órgãos governamentais norte-americanos, no âmbito federal, começam também a adotar o modelo P-CMM, como guia das ações administrativas para gerenciar e desenvolver seus quadros profissionais (Curtis et al., 2003). O próprio Governo Federal brasileiro já vem adotando o modelo básico CMM como guia para selecionar empresas de software prestadoras de serviço e para determinar 
padrões de qualidade em projetos de desenvolvimento de software patrocinados pelo Governo Federal (Ministério da Ciência e Tecnologia, 2006).

\section{CONSIDERAÇÕES FINAIS}

Os modelos multiestágios buscam oferecer um referencial teórico para o desenvolvimento dos processos organizacionais a partir de duas dimensões essenciais: a flexibilidade e a controlabilidade, ou seja, são modelos que permitem uma compreensão das fases maturacionais pelas quais as organizações possivelmente passam, produzindo uma projeção futura ou provável das adaptações sucessivas e necessárias para a efetiva orientação e dirigibilidade da empresa, em termos da melhoria dos seus processos internos rumo à excelência e à eficácia gerencial. Dessa forma, tais modelos fornecem indicadores de desempenho e de ações que possibilitam o planejamento antecipado das ações gerenciais, tornando os esforços da gestão mais efetivos, mais econômicos e mais controláveis.

O grande valor dos modelos, baseados em níveis ou estágios de maturidade, está na sua capacidade de dotar as organizações de orientações para desenvolver, consistentemente, os seus processos, o que implica que estes venham a ser documentados, mensurados, controlados e continuamente melhorados ao longo do tempo (PMI, 2005). Em virtude desta conotação estratégica, os modelos de maturidade surgem como solução para estabelecer um plano de ação organizado, capaz de permitir que a empresa atinja as metas definidas pela alta direção (Cleland \& Ireland, 2006).

Dentre os benefícios advindos pela utilização de modelos de maturidade nas organizações, podem-se destacar: a) avaliação da empresa, em termos de suas práticas em gerenciamento de processos; b) comparação de seu nível de maturidade em relação a organizações similares; c) entendimento das forças e fraquezas de seus processos de trabalho; d) desenvolvimento de plano de ação para sua capacitação continuada dos funcionários da organização; e e) redução de custos e retrabalhos ao direcionar as prioridades da ação gerencial (White \& Yosua, 2001).

Os processos de gestão de pessoas, por sua vez, demandam, cada vez mais, abordagens teóricas e o desenvolvimento de modelos orientados para a mensuração de seus resultados, bem como para ações permanentes que resultem em aplicação da força de trabalho e capacidade gerencial das pessoas de forma alinhada à estratégia corporativa. Nesse sentido, os modelos multiestágio são relevantes ao permitir projeções futuras e quantificação dos níveis de eficiência e eficácia das ações em gestão de pessoas, atrelando medidas de desempenho às estratégias competitivas e fornecendo maior nível de planejamento e previsibilidade da ação gerencial.

Observa-se que a metodologia do P-CMM se mostra como instrumento de interesse na gestão de pessoas ao fornecer uma caracterização - ao mesmo tempo abrangente e detalhada - dos níveis de maturidade das práticas adotadas pela organização, estabelecendo um programa de contínuo desenvolvimento da força de trabalho, priorizando pontos para ações de melhoria e integrando o desenvolvimento das pessoas com o desenvolvimento e evolução dos processos de trabalho.

Finalmente, acredita-se que a continuidade de pesquisas orientadas para o desenvolvimento de novos e melhores modelos multiestágios de maturidade possam contribuir para o princípio da melhoria contínua em processos de gestão de pessoas e para o alinhamento desses processos à estratégia corporativa das organizações.

Artigo recebido em 14.11.2006. Aprovado em 03.07.2007. 


\section{REFERENCIAS BIBLIOGRÁFICAS}

Abernathy, W. J. (1976). Production process, structure and technological change. Decision Science, 7(4), 607-618.

Adizes, I. (1979). Organizational passages: diagnosing and treating lifecycle problems of organizations. Organizational Dynamics, 8(1), 3-25.

Bressant, J., Caffyn, S., \& Gallagher, M. (2001). An evolutionary model of continuous improvement behavior. Technovation, 21(2), 67-77.

Burn, J. M. A. (1994). Revolutionary staged growth model of information systems planning. Proceedings of the International Conference on Information Systems, Vancouver, Canada, 15.

Carnegie-Mellon University, Software Engineering Institute. (2000). Technical report CMU/SEI2000-TR-018. Recuperado em 25 novembro, 2000, de http://www.sei.cmu.edu/pub/documents/00.reports/pdf/00tr018.pdf

Chandler, A. D. (1962). Strategy and structure. Cambridge, MA: MIT Press.

Cleland, D. I., \& Ireland, L. R. (2006). Project management: strategic design and implementation (5th ed.). New York: McGraw-Hill.

Crosby, P. B. (1979). Qualidade é investimento. Rio de Janeiro: José Olympio.

Curtis, B., Hefley, W. E., \& Miller, S. (1995). Overview of the people capability maturity model. Software Engineering Institute / Carnegie-Mellon University. Pittsburgh, Pennsylvania. $\begin{array}{lllll}\text { Recuperado em } & 9 & \text { novembro, } & \text { de }\end{array}$ http://www.sei.cmu.edu/pub/documents/95.reports/pdf/mm001.95.pdf

Curtis, B., Hefley, W. E., \& Miller, S. A. (2002). People capability maturity model: guidelines for improving the work force. Reading, MA: Addison Wesley.

Curtis, B., Hefley, W. E., \& Miller, S. A. (2003, Abril). Experiences applying the people capability maturity model. Crosstalk: The Journal of Defense Software Engineering. Recuperado em 3 agosto, 2003, de http://www.stsc.hill.af.mil/crosstalk/2003/04/curtis.html

Dutra, J. S. (2002). Gestão de pessoas: modelo, processos, tendências e perspectivas. São Paulo: Atlas.

Earthy, J. V., Bowler, Y., Forster, M., \& Taylor, R. (1999, Junho). A human factors integration capability maturity model. International Conference on People in Control (Human Interfaces in Control Rooms, Cockpits and Command Centres). Bath, Reino Unido. Recuperado em 20 novembro, 2000, de http://link.aip.org/link/abstract/IEECPS/v1999/iCP463/p320/s1

Galbraith, J. (1982). The stage of growth. Business Strategy, 3(1), 70-79.

Garrett, G. A., \& Rendon, R. G. (2005). Managing contracts in turbulent times: the contract management maturity model. Contract Management, 45(9), 48-57.

Greiner, L. E. (1972). Evolution and revolution as organizations grow. Harvard Business Review, 50(4), 37-46.

Haire, M. (1959). Biological models and empirical history of the growth of organizations. In. M. Haire (Ed.). Modern organizational theory (pp. 272-306). New York: John Wiley \& Sons. 
Humphrey, W. S. (1997). Managing technical people: innovation, teamwork, and the software process. Reading, MA: Addison-Wesley.

Kimberly, J., \& Miles, R. (1980). The organizational life cycle. San Francisco: Jossey-Bass.

Kohlberg, L. (1969). Stage and sequence: the cognitive developmental approach to socialization. New York: Rand McNally.

Kuznets, S. (1965). Economic growth and structure: selected essays. New York: W. W. Norton.

Laszlo, A. (2003). Evolutionary systems design: a praxis for sustainable development. Journal of Organizational Transformation \& Social Change, 1(1), 29-46.

Lavoie, D., \& Culbert, S. A. (1978). Stages of organization and development. Human Relations, 31(5), 417-438.

Lockamy, A., \& Mccormack, K. (2004). The development of a supply chain management process maturity model using the concepts of business process orientation. Supply Chain Management: An International Journal, 9(4), 272-278.

Marques, A. C. F. (1994). Deterioração organizacional: como detectar e resolver problemas de deterioração e obsolescência organizacional. São Paulo: Makron Books.

Ministério da Ciência e Tecnologia. (2006). Programa Brasileiro da Qualidade e Produtividade em Software - PBQP Software. Secretaria de Política de Informática. Recuperado em 15 outubro, 2006, de http://www.mct.gov.br/index.php/content/view/47817.html

Mintzberg, H. (1973). Strategy making in three modes. California Management Review, 16(2), 44-53.

Mount, J., Zinger, J. T., \& Forsyth, G. R. (1993). Organizing for development in the small business. Long Range Planning, 26(5), 111-120.

Neuhauser, C. (2004). A maturity model: does it provide a path for online course design? The Journal of Interactive Online Learning, 1(3), 1-17.

Nolan, R. L. (1973). Managing the computer resource: a stage hypothesis. Communications of the $A C M, 16(7), 399-405$.

Petrick, J. A., \& Wagley, R. A. (1992). Enhancing the responsible strategic management of organizations. Journal of Management Development, 11(4), 57-72.

Project Management Institute. (2005). Organizational project management maturity model. Recuperado em $15 \quad$ julho, 2005, de http://www.pmi.org/BusinessSolutions/Pages/Organizational-Project-Management-MaturityModel.aspx

Scott, B. R. (1971). Stages of corporate development. Boston: Harvard Business School, Intercollegiate Case Clearing House.

Scott, M., \& Bruce, R. (1987). Five stages of growth in small business. Long Range Planning, 20(3), 45-52.

Smith, K. G., Mitchell, T. R., \& Summer, C. E. (1985). Top level management priorities in different stages of the organizational life cycle. Academy of Management Journal, 28(4), 799-821.

Urdang, L., \& Flexner, S. B. (1968). The Random House dictionary of the english language: College edition. New York: Random House. 
Vakaslahti, P. (1997). Process improvement frameworks: a small case study with people capability maturity model. Software Process: Improvement and practice, 3(4), 225-234.

Visconti, M., \& Cook, C. R. (1998). Evolution of maturity model: critical evaluation and lessons learned. Software Quality Journal, 7(3/4), 223-237.

White, K. R. J., \& Yosua, D. (2001, Maio). Describing project management maturity. Havertown, PA: PMSolutions White Paper. 